\title{
A LÓGICA DEDUTIVA SOB A ÓTICA DA INTERPRETAÇÃO JURÍDICA E DA TEORIA DA DECISÃO
}

Ana Augusta Rodrigues Westin Ebaid

Professora do núcleo de pesquisa e extensão em direito da UNOESTE e mestranda pelo Centro Universitário Eurípedes de Marília UNIVEM

\section{RESUMO}

Este artigo versa sobre a aplicação do raciocínio lógico dedutivo na interpretação e decisão jurídica, com enfoque no positivismo jurídico e sua base de constituição em um Estado Democrático de Direito. $O$ trabalho se propõe a examinar os contornos do positivismo jurídico sob a ótica de um dos seus maiores críticos: o filósofo Chaïm Perelman. A investigação parte do estudo da lógica dedutiva e indutiva, examinando sua relação com o direito, visando atingir uma teoria jurídica que atinja os ideais filosóficos e políticos de um Estado Democrático de Direito. O resultado da investigação aponta que, apesar do método lógico dedutivo desenvolver-se como um instrumento importante no mundo jurídico, ele não é suficiente para expressar de modo adequado um sistema complexo que envolve, acima de tudo, valores cujo escopo é atingir a realização da justiça.

Palavras-chave: Lógica Dedutiva; Positivismo Jurídico; Estado Democrático.

THE DEDUCTIVE LOGIC IN LEGAL INTERPRETATION

\begin{abstract}
This paper discusses the application of deductive logical reasoning in the interpretation and legal decision, focusing on legal positivism and its base of constitution in a democratic state. The study aims to examine the contours of legal positivism from the perspective of one of its biggest critics: the philosopher Chaïm Perelman. The investigation begins with the study of deductive and inductive logic, examining its relationship with the law, to achieve a legal theory that reaches the philosophical and political ideals of a democratic state. The research indicates that despite the logical deductive method to develop as an important tool in the legal world, it is not enough to express adequately a complex system that involves, above all, values whose goal is to achieve the realization of justice.
\end{abstract}

Keywords: Deductive Logical; Legal Positivism; Democratic State. 


\section{INTRODUÇÃO}

No Estado declarado democrático de direito, a normatividade jurídica impera por meio de uma teoria discursiva, que sustenta a eficiência jurídica embasada em um sistema jurídico rigoroso e avesso em pautar fundamento numa lógica diversa que não seja a concretização efetiva das leis.

Neste trabalho busca-se investigar os contornos do sistema jurídico positivista, associado à lógica, coerência e estabilidade das decisões judiciais. Sustenta-se que 0 ato decisório é um dos procedimentos mais fundamentais da instância judicial, cuja detenção fica a cargo exclusivo do juiz.

Desse modo, o objetivo deste estudo é apontar os contornos do ordenamento jurídico e da lógica, não se referindo apenas à lógica dedutiva e seu silogismo categórico que usualmente é assumida nos argumentos jurídicos, mas também à lógica jurídica.

Parece interessante examinar o problema do fenômeno da positivação do direito sob a ótica do filósofo Chaïm Perelman, fixando os limites colocados no raciocínio jurídico e na aplicação do direito, visando a atingir uma teoria jurídica que atenda aos ideais de um Estado Democrático de Direito.

Verifica-se, portanto, que não há como compreender um Estado Democrático de Direito onde é característico no sistema jurídico o imediatismo de valores, metas e silogismos.

\section{DIREITO E LÓGICA}

Historicamente, o campo de conhecimento da lógica surgiu na Grécia Antiga e teve como seu mais típico representante Aristóteles. A princípio foi considerada como um ramo da filosofia, tendo como principal objetivo estabelecer condições formais para validade de determinado raciocínio.
No âmbito do estudo da lógica, se considera verdadeira a sentença ou o enunciado cujo conteúdo expressa a realidade do mundo e seus objetos, ao passo que é considerado como falsa a sentença ou enunciado cujo conteúdo não expressa adequadamente a realidade do mundo e os seus objetos. Portanto, para a lógica, argumentos são o conjunto de afirmações constituídas por premissas que decorrem uma conclusão.

É comum ouvir falar a respeito de lógica dedutiva (dedução) e lógica indutiva (indução). Em linhas gerais, entende-se que a primeira parte de premissas gerais para se chegar a um resultado ou afirmação particular, ao passo que a segunda parte de fatos específicos para se chegar a uma premissa geral.

A lógica dedutiva, na verdade, é muito mais complexa, pois não existe uma ordem seqüencial entre as premissas ou até mesmo entre as premissas e a conclusão, mas desta lógica decorrem conclusões necessárias. Já a lógica indutiva não se trata de uma lógica em sentido estrito, pois através dela não se extrai uma conclusão inequívoca ou necessária, mas apenas uma idéia de fé e crença que são abstraídas das experiências.

Para o filósofo Irving Copi: "Um argumento dedutivo válido constitui uma prova ou demonstração, mas um argumento indutivo é, no máximo, altamente provável". (COPI, 1978. p. 364)

A partir do renascimento foi acentuada a discussão sobre qual método deveria presidir o conhecimento. Existiam aqueles que defendiam o método dedutivo, identificados como racionalistas, tendo em René Descartes sua expressão máxima, e aqueles que defendiam ser apropriado o método indutivo, identificados como empiristas, tendo como representante John Locke. 
Desta forma, o que interessa destacar é que na maioria dos sistemas jurídicos atuais, inclusive no sistema jurídico pátrio, onde a lei tornou-se a principal fonte, prevalece nas petições, defesas e decisões a lógica do tipo dedutivo.

\section{ESCOLA DA EXEGESE: A ORIGEM DO LEGALISMO}

No sistema jurídico pátrio, no que se refere à questão das decisões judiciais, prevalece o ideal máximo da segurança jurídica, ficando nitidamente marcado os contornos teóricos do positivismo jurídico. Justamente por receber a influência deste sistema, em tese não há a atividade de interpretação propriamente dita, pois qualquer interpretação deveria ensejar alguma liberdade de escolha, ou compreensão subjetiva, não condizendo com a idéia de certeza que se alcança através do raciocínio dedutivo.

Nota-se que diferentes juízes exercendo suas atividades, seja individual ou coletivamente, chegam sempre às mesmas conclusões embasadas no universo das legislações vigentes nos julgamentos das demandas.

Assim, nas sociedades onde se preza por um sistema que visa apenas à inequivocabilidade e a segurança jurídica das decisões judiciais, a lógica dedutiva passa a ser entendida como a própria lógica das decisões judiciais, reduzindo por assim dizer a atividade do juiz em uma mecânica aplicação de normas.

O exemplo clássico desta perseguição pela certeza das decisões judiciais foi conhecido pela Escola Exegética de direito, que surgiu após as conquistas da Revolução Francesa e com a consagração do Código de Napoleão. Foi através desta escola que ocorreu o fenômeno da positivação do direito.

Como observação histórica, o positivismo da Escola Exegética veio para atender aos interesses da nova classe burguesa instituída pela Revolução Francesa, pois desconfiavam que a classe dos juízes ainda estivesse vinculada aos ideais do antigo regime.

Em relação a este contexto histórico, Chaïm Perelman, em seu livro intitulado de Lógica Jurídica, situa o aparecimento da Escola Exegética.

Esta escola pretendia realizar o objetivo a que se propuseram os homens da Revolução, reduzir o direito à lei, de modo mais particular, o direito civil ao Código de Napoleão. [...] "Toda a lei, tanto no espírito quanto na letra, com uma ampla aplicação de seus princípios e o mais completo desenvolvimento das consequências que dela decorrem, porém nada mais que a lei, tal foi a divisa dos professores do Código de Napoleão." [...] limitamos aos anos de 1830-1880 o período em que a escola da exegese impôs de modo absoluto, suas técnicas de raciocínio jurídico. Estas eram fundamentadas, como ainda escrevia Laurent em 1878, na idéia de que "os códigos nada deixam ao arbítrio do interprete" e que apenas em casos deveras excepcionais a lei era verdadeiramente insuficiente. (PERELMAN, 2004, p. 31-32).

As premissas desse horizonte cultural limitaram espaço ao livre arbítrio ou a interpretação do juiz, passando a singela ideia de que não se estava à mercê dos homens, e, sim, ao abrigo das instituições de natureza impessoal. Sendo assim, seguindo esta concepção, a atividade do juiz se limitava a aplicar o direito que foi dado.

Nessa ordem de ideias, torna-se pertinente aludir-se às reflexões provocadas por Chaïm Perelman:

Quer seja considerado um sistema dedutivo, quer seja assimilado como uma pesagem, 0 ato de distribuir justiça, o juiz parece tomar 
parte de uma operação de natureza impessoal, que the permitirá pesar as pretensões das partes, a gravidade dos delitos etc ... Mas, para que a pesagem seja feita de modo imparcial, desprovido de paixão - o que quer dizer sem temor, sem ódio e também sem piedade -, é necessário que a justiça tenha os olhos vedados, que não veja as consequências do que faz: dura lex, sed lex. Temos aqui uma tentativa de aproximar o direito quer de um cálculo quer de uma pesagem, seja como for de algo cuja tranquilizadora exatidão deveria poder proteger-nos contra o abuso de uma justiça corrompida, como a do Antigo Regime. (PERELMAN, 2004, p. 33)

Os juristas da escola da exegese empenharam o seu trabalho em procurar limitar 0 papel do juiz ao estabelecimento dos fatos à subsunção das leis. Deste modo, uma vez estabelecidos os fatos, bastava formular-se 0 silogismo judiciário, onde a premissa maior representaria a regra de direito, enquanto a premissa menor consistia na adequação da regra ao fato, e a decisão decorria da conclusão desse silogismo.

A ideia era fornecer ao juiz e aos litigantes um instrumento perfeito, contendo um conjunto de regras coerentes e completas, onde todas as decisões jurídicas poderiam ser obtidas mediante silogismos.

Estes foram os pontos de vista que predominaram na doutrina francesa, no início do século XIX. Os juízes estavam limitados a fazer sua exposição e interpretação, seguindo orientações dos códigos.

Contudo, apesar da ousadia dessa escola, muitos problemas também foram aparecendo, visto que, mesmo quando se tratava de compreender e aplicar um texto legal, iam surgindo dificuldades que não podiam ser sanadas com a mera técnica de aplicação de subsunção.

Diante deste quadro, numerosas críticas foram surgindo, a lei codificada foi-se tornando cada vez mais inadequada, acarretando, por sua vez, o perecimento da escola da exegese, que dominou o pensamento jurídico-europeu na primeira metade do século XIX.

Após esse período, o direito foi sendo transformado em um saber dogmático, revelado por seu sentido mais estrito como ciência positiva das normas.

O modelo da dogmática jurídica sempre foi objeto de numerosas críticas. "A objeção mais importante consiste em que unicamente com os meios da análise lógica e da dedução lógica não se podem alcançar novos conceitos normativos." (ROBERT, 2005, p. 247)

\section{A LÓGICA DEDUTIVA NA INTERPRETAÇAO E DECISÃO JURÍDICA}

A ideia de que a lógica dedutiva deva embasar as decisões judiciais vem sendo ferozmente atacada pela teoria do direito contemporâneo. A aplicação do direito, visando somente à obediência das leis, é uma visão retrógrada, que muitas vezes não consegue atingir sua maior finalidade, que é a realização da justiça.

Para isso, um novo cenário jurídico passa a ser constituído, marcando o desenvolvimento do discurso jurídico, com a finalidade de trabalhar com questões que envolvem a apreciação de juízos de valor e sob as quais não se podem subtrair conclusões lógicas ou formais.

É neste sentido que Chaïm Perelman aponta que a finalidade do direito é buscar a realização da justiça, não apenas recorrendo a aplicação das normas aos fatos, mas ligar intrinsecamente o valor ao direito.

Para este autor a decisão jurídica decorre de um raciocínio prático. Neste sentido, observa 
que a interpretação dos fatos exige um tipo de operação mental que não se identifica com aplicação do raciocínio lógico dedutivo. Por esta razão sustenta a impossibilidade da lógica dedutiva ser constituída como o método por excelência adotado nas decisões judiciais.

A forma de raciocínio proposto por Chaïm Peralman se fundamenta nos argumentos, observando quais são os elementos mais ou menos eficientes que convencerão o juiz no momento da decisão.

$\mathrm{Na}$ concepção desse autor o raciocínio jurídico não pode ser reduzido a proposições silogísticas. Desse modo, dizer que existe um objeto específico para o conhecimento do direito seria uma postulação vazia de conteúdo, tendo em vista que o Direito é uma ciência que permanece em constante mutação. O liame de suas idéias consiste em demonstrar a impossibilidade de existirem interpretações jurídicas, obtidas como "verdades absolutas".

Decidir uma questão judicial é um processo que envolve, exclusivamente, o convencimento. Assim, as partes utilizam-se das técnicas argumentativas, visando a convencer o juiz e os tribunais superiores sobre a relevância das suas teses, tendo em vista obterem sucesso nos seus julgamentos.

$\mathrm{Na}$ realidade, esses argumentos podem persuadir, de forma convincente, no mundo jurídico, permitindo que novas interpretações de leis, novas jurisprudências sejam construídas, ajudando na construção de uma vida jurídica, adequando a aplicação do direito à realidade social.

\section{CONCLUSÃO}

Existe certo distanciamento entre os ideais de um Estado Democrático e suas bases teóricas e filosóficas, assim, o que está faltando nesta conjectura errônea é a revalorização das idéias de realização do direito.
A aplicação do direito visando somente à obediência das leis muitas vezes não consegue atingir sua maior finalidade, que é a realização da justiça. Para isto, torna-se necessário rompermos com esta concepção arcaica de produção, interpretação e aplicação das leis, procurando condicionar as decisões judiciais à procura do justo e dentro do contexto da realidade social.

Conforme visto, a ruína da Escola da Exegética se deu em razão das mudanças de ares no panorama jurídico-social e também pela impossibilidade intrínseca de sustentação do método dedutivo. Este método representou um instrumento de diminuição do escopo da interpretação do magistrado, bem como seu livrearbítrio, o que não deixou de ser sentido no contexto do ambiente pós-revolucionário.

Desta forma, torna-se problemático compreender um Estado Democrático de Direito onde são proferidas decisões judiciais com observância de metas e silogismos.

\section{REFERÊNCIAS}

COPI, I. M. Introdução à Lógica. 2.ed. São Paulo: Mestre Jou, 1978.

DESCARTES, R. Discurso do Método. In: DESCARTES. 3.ed. São Paulo: Abril Cultural, 1983. p. 25-71. (Os Pensadores, v. 14).

FERRAZ JR., T. S. Introdução ao Estudo do Direito. In: Técnica, Decisão, Dominação. 4.ed. rev. ampl. São Paulo: Atlas, 2003.

FERRAZ JR., T. S. A Ciência do Direito. 2.ed. São Paulo: Atlas, 2006.

HABERMANS, J. Direito e Democracia. In: ENTRE Facticidade E Validade. Rio de Janeiro: Tempo Brasileiro, 1997. v.II.

KELSEN, H. Teoria Pura do Direito. São Paulo: Martins Fontes, 1998.

LEAL, R. P. L. Teoria Processual da Decisão Jurídica. São Paulo: Landy Editora, 2002.

LOCKE, J. Ensaio acerca do entendimento humano. In: Loche. 2.ed. São Paulo: Abril Cultural, 1983. p. 133-344. (Os Pensadores, v. 18). 
PERELMAN, C. Lógica Jurídica. 2.ed. São Paulo: Martins Fontes, 2004.

PERELMAN, C. Retóricas. 2.ed. São Paulo: Martins Fontes, 2004.

PERELMAN, C. Lógica Jurídica. 2.ed. São Paulo: Martins Fontes, 2004.

PERELMAN, C. OLBRECHTS-TYTECA, Tratado da Argumentação: A nova Retórica. 2.ed. São Paulo: Martins Fontes, 2002.

RADBRUCH, G. Filosofia do Direito. São Paulo: Martins Fontes, 2004.

RIGAUX, F. A Lei dos Juízes. São Paulo: Martins Fontes, 2003. 